12th LUMEN International Scientific Conference Rethinking Social Action. Core Values in Practice | RSACVP 2019 | 15-17 May 2019 | lasi-Romania

\title{
Addressing the Acceptance of Students 'Studies in Other Countries in the Context of National Policies and Security Strategies
}

\author{
Casen PANAITESCU
}

https://doi.org/10.18662/lumproc. 170

How to cite: Panaitescu, C. (2019). Addressing the Acceptance of Students 'Studies in Other Countries in the Context of National Policies and Security Strategies. In C. Ignatescu (ed.), 12th LUMEN International Scientific Conference Rethinking Social Action. Core Values in Practice, 15-17 May 2019, Iasi - Romania (pp. 239-245). Iasi, Romania: LUMEN Proceedings. https://doi.org/10.18662/lumproc.170 



\title{
Addressing the Acceptance of Students 'Studies in Other Countries in the Context of National Policies and Security Strategies
}

\author{
Casen PANAITESCU ${ }^{1}$
}

\begin{abstract}
Access to education outside applicants' country of origin has increased in recent years for some countries, but has also created numerous barriers for others. Thus, for certain specializations, age groups have become representative. Countries with lower taxes and engineering specialties sought on the labor market have applicants from the age group 25-34 years. The other developed countries have a higher proportion of older students in $M A$ and other postgraduate studies, including doctorate. Such countries are Australia, Germany, the Netherlands.

The participation of foreign students in the education system does not take into account the traditional view. Thus, in this paper, a non-random component was developed that uses two tools as evaluation tools: state laws where the prospective student applies and proximity to the applicant's university.
\end{abstract}

Keywords: Students ; security ; international relations ; strategies.

\section{Introduction}

Initially, education experts argued that involving foreign students in increasing social diversity and heterogeneity is an approach that only takes into account the needs of students. It was later found that access to education is based on the entire socio-economic context. Each social group of foreign students will consider both the academic capacity of training, the motivation and the possibility of matching the studies, the ease in preparing the dossier, the possibility of social integration, the teaching methods (language, level).

The access to education outside applicants' country of origin has increased in recent years for some countries, but has also created numerous

\footnotetext{
1 Petroleum-Gas University of Ploieşti, Romania, Ploiesti, Romania, cpanaitescu@upgploiesti.ro 
barriers for others. Thus, for certain specializations, age groups have become representative. Countries with lower taxes and engineering specialties sought on the labor market have applicants from the age group 25-34 years. The other developed countries have a higher proportion of older students in MA and other postgraduate studies, including doctorate. Such countries are Australia, Germany, the Netherlands [1].

The participation of foreign students in the education system does not take into account the traditional view. Thus, a non-random component has been developed that uses two instruments as assessment tools: the laws of the state where the student is applying and the proximity to the applicant's university. In 2004, Milligan noticed that proper instrumentation of education through viable, long-term legislation can increase predictability in the field of education [2, 3]. Thus, in 2010 it went so far as to link the graduation rates of students studying abroad and their votes.

\section{Theoretical Background}

The policies and strategies of universities in the European Union to attract foreign students to studies vary from one year to another. Although in general the entire European space applies theoretically the same policies the institutions of the member states through the autonomy of the local waters that try to find solutions for increasing the number of foreign students in the long term. European education policies are based on international agreements concluded at the level of education ministries as well as on bilateral agreements with partners outside the European area. Foreign students come from: Tunisia, India, Israel, Iraq, Syria, South Africa. The existence of Erasmus + mobility programs with partner countries of the program allows for study periods at partner universities across the EU and the use of the ECTS transfer credit system.

\section{Acceptance of Students 'Studies in Other Countries}

In the countries where the education system has been centralized, its decentralization and the creation of local autonomy has created the impression that both learning and social freedom will lead to a greater number of foreign students. But it has been found that it is mandatory to have competent local authorities and the necessary means needed to manage the resources for this decentralization. If this has not been done, decentralization has become a burden for some universities. For universities that have made a connection with local and regional authorities, decentralization has been a turning point. In this case, education reform has attracted important incomes from foreign students for certain 
specializations. An example in this regard is the former GDR, where the government has given the local councils authority over universities, and the reforms have been punctual.

Governments need to develop a new role as supervisory authorities. It must establish the parameters by removing the chaotic and unplanned diversity, which is in fact the main barrier of the foreign applicant. If he does not understand the educational offer and is not motivated, neither the choice he will make will be favorable to some universities although they have an interesting educational offer. In order to eliminate the burdens placed on future students, higher education systems and the state must be based on:

- sufficient autonomy;

- (stratification) explicit hierarchy because universities compete with each other for funding and attracting students;

- cooperation between universities;

- greater openness to deepen the dialogue with the society;

- respecting the principles of a good governance;

- effective management of scarce resources: for example, students of the preparatory year can study in other universities, other than those were they will study a particular specialization. But the role of the government must not be eliminated, since policies, standards and regulations must be established.

The wars that took place in Slovenia and Croatia have reduced the number of foreign students. Macedonia, which has no armed conflicts but has political and economical conflicts, is not attractive and has a small number of foreign students. Issues such as the boycott of guardianship companies, the refusal to accept ethnic and religious minorities are exceptions in the university environment.

In the Bologna system, to which more and more countries have joined, mechanisms have been put in place that should contribute to the dismantling of learning barriers and recognition of diplomas. The European Credit Transfer System (ECTS) and the curricular renewal are priorities that are part of public responsibility. But a negative effect of this program was the division of some universities, the exodus of pupils and teachers, the difficulty of maintaining the quality of education.

However, establishing clear accreditation procedures ensures quality in higher education. European experts have already felt the danger of a purely formal reform: cutting and gluing curricula, university programs without basic elements in the labor market, etc.

In Romania the competent authorities for the regulated professions ensure the automatic recognition of qualifications by assessing the minimum 
training requirements established for these professions in the EU, EEA and EC Member States. CNRED operates within the Ministry of Education, Research, Youth and Sport and is a member of the European Network ENIC / NARIC of National Recognition Centers (NARIC - National Academic Recognition Information Centres, ENIC - European Network of Information Centres). Equivalence is the process of evaluating all components of the study program as well as the learning outcomes and compatibility with the study program in the Romanian higher education system, taking into account the admission requirements for the respective study program, which can be completed with the issuance of a certificate entitling the holder to the same rights regarding the continuation of the studies and/or access to the labor market. Recognition consists in the assessment and compatibility of the level, field and/or specialization of the study document obtained abroad with the national education system.

With regard to the social dimension of education reflected in the policies of the European institutions, the most important strategy launched by the European Commission for this decade - Europe 2020, sets among the 5 main objectives of the European Union's smart, sustainable and inclusive development, the growth of the population with higher education studies aged 30-34 years, up to at least $40 \%[4,5]$.

A student who uses multiple platforms may have access to increased potential capital compared to those who are reluctant to use computermediated communication. Online platforms help and keep in touch with individuals in a community from which one was part of and left at one time.

Researches in the field have shown that various forms of social capital (links with friends, neighbors, family) are an indicator of the wellbeing of individuals (self-respect, personal satisfaction, etc.).

Immigrants' access to the Romanian education system takes place in the context of ensuring the conditions for the integration of foreigners who have been granted a right of residence in Romania, in the country's economic, social and cultural life. According to the provisions of the National Education Law, compulsory education in Romania is of 10 grades and includes primary, secondary and high school education. At the age of 18, the obligation to attend 10-grade education and frequent courses, ceases. Migrants must bring their diploma from home. If these cannot be brought, the EU proposes "special methods of recognition of diplomas": selfdeclarations, exams, interviews with university professors, etc.

However, the attraction of foreign students to studies in Romania has not been a vital priority for some universities, who have satisfied themselves with the domestic offer, without taking into account the fact that the tradition of a large number of foreign students is not compulsory. This 
can only be maintained by implementing policies based on strategies for attracting foreign students.

According to specialty studies, there are the following forms of internationalization of higher education: physical mobility, cross-border recognition of qualifications, curricular reform, promotion of the European Higher Education Area agenda for increasing mutual trust between institutions providing tertiary education in different countries, academic and scientific marketing and the promotion abroad of the provision of higher education, the relatively recent development of some cross-border activities and of some forms of institutional mobility for the provision of study programs abroad.

Most admission examinations at the university do not test the intellectual ability (the ability to make the pupil learn something), but test retention (through exams in history, Bulgarian, chemistry, geography, etc.), success depending on the ability to reproduce correctly previous knowledge. This kind of KNOWLEDGE in Bulgarian higher education is the signal the potential student expects to do in the future. Moreover, this does not mean that a discipline is a set of knowledge and abilities to be retained, but rather as expectations and peculiarities from those who learn it to be satisfied $[6,7]$.

Bulgaria supported bilateral agreements. That have an important impact in supporting cultural and educational diversification in the region.

The Ministry's actions in the field of international mobility in the higher field are based on:

- encouraging and supporting the mobility of young people in Bulgaria, including students, volunteers, working youth and their families;

- encouraging and supporting knowledge about the different ethnic communities and their structures and cultures to build tolerance, understanding and interaction among themselves;

- expanding European cooperation in the youth field;

- encouraging and supporting the identification of young people with European citizenship and the learning of new languages and cultures;

- developing working skills in a multicultural and multinational environment.

Regarding multilateral initiatives, Bulgaria participates in the CEEPUS program operating in the Central and Eastern Europe Region. As a member state of the EU, the country also has the right to participate in Erasmus, Marie Curie, etc. With regard to unilateral initiatives, Bulgaria is in active cooperation with the US through the Fulbright Program. A number of national programs also offer scholarships to Bulgarian students for study and / or complete research in countries such as Serbia, Moldova, Thailand, the Russian Federation, the Republic of South Korea and Mexico. As for 
students entering the market, there are mobility programs with countries such as Moldova, Armenia, Macedonia, the CEEPUS countries and the French-speaking countries (through Bulgaria's participation in the AUF) [8]. Recognition of studies in the EU is due to the legislation in force governing the award of diplomas. Admission of migrants to study in universities in Bulgaria is in accordance with Art. 9/2 and 2018/381 / EC. Usually, foreign students enrolle in the consulates of the countries of origin, for the scholarships offered by the Bulgarian state. Then the selection and granting of the visa is made much easier than in Romania. Consulates grant study visas to foreign students within 35 business days.

\section{Conclusions}

Permanent residence permit may be granted to foreigners who apply and take visa and become students. Foreign students benefit by Visa and they have the same rights as the citizens of that country through their residence permit.

In the countries with fragmented and polarized political parties, where governments are facing large political governance issues, the opposition has put a strong stance in the legislation. Serious internal riots create barriers to education for the surrounding countries and not only. The generation of tensions in the economy also spreads in education, increasing the hostility of teachers, the uncertainty of foreign students due to the constantly changing laws and implicitly the reduction of the number of students. Improving executive-legislative relations leads to widespread polarity and the prestige of educational reforms that are reflected in the access to education for those who want to study in a safe and stable area. Serious internal riots only create barriers to education for the surrounding countries. Students do not have to waste time to improve an institution. They need to obtain skills and qualifications that enable them to achieve their goals in life. Students should benefit from:

- increase competencies;

- integration in one of dynamic society and democratic.

\section{References}

[1] Denson N, Bowman N. University diversity and preparation for a global society: The role of diversity in shaping intergroup attitudes and civic outcomes. Studies in Higher Education. 2013;38(4):555-570.

[2] Karkouti IM. Black students' educational experiences in predominantly white universities: A review of the related literature. College Student Journal. 2016;50(1):59-70. 
[3] Maramba DC, Velasquez P. Influences of the campus experience on the ethnic identity development of students of color. Education and Urban Society. 2012;44(3):294-317.

[4] Nguyen AMD, Benet- Martinez V. Biculturalism and adjustment: A metaanalysis. Journal of Cross-Cultural Psychology. 2013;44(1):122-159.

[5] Grigorieff A, Roth C, Ubfal D. Does Information Change Attitudes Towards Immigrants? Representative Evidence from Survey Experiments. SSRN Electronic Journal [Internet]. 2018. Available from: https://ssrn.com/abstract=2889665

[6] Freedom of the Press 2017 [nternet]. Freedom House; 2017. Available from: https://freedomhouse.org/sites/default/files/FOTP_2017_booklet_FINAL_ April28.pdf.

[7] G20 International Migration and Displacement Trends Report 2018 [Internet]. Available from: http://www.oecd.org/els/mig/G20-international-migrationand-displacement-trends-report-2018.pdf

[8] UNHCR, OECD. Engaging with employers in the hiring of refugees. A 10point multi-stakeholder action plan for employers, refugees, governments and civil society; 2018. Available from:

http://www.oecd.org/els/mig/UNHCROECD-Engaging-with-employers-inthe-hiring-of-refugees.pdf 